\title{
Plantas Alimentícias Não Convencionais (PANCs): levantamento em zonas urbanas de Santana do Livramento, RS
}

\author{
Unconventional Food Plants (UFPs): survey in urban zones of Santana do \\ Livramento, RS
}

\author{
Simone Braga Terra' $(*)$ \\ Carla Thais Rodrigues Viera
}

\section{Resumo}

Diversas plantas são consideradas invasoras e até nocivas, pelo fato de ocorrerem entre plantas cultivadas ou em outros lugares considerados inadequados. Estas plantas são controladas com enxadas, tratores, pisoteio e herbicidas, objetivando a inibição do seu crescimento e a erradicação definitiva. Entretanto, muitas destas espécies vegetais de crescimento espontâneo possuem importância cultural, ecológica e econômica, podendo algumas serem consideradas como alimentícias. A pesquisa objetivou realizar o levantamento das PANCs que surgem espontaneamente no perímetro urbano do município de Santana do Livramento, RS. Foi realizado um levantamento bibliográfico sobre as principais PANCs do Rio Grande do Sul, concomitantemente às saídas na zona urbana no município, contemplando terrenos baldios, calçadas e acostamento de ruas e um parque municipal, visando à identificação botânica, coleta e levantamento das PANCs de maior ocorrência. Foram coletadas e identificadas treze PANCs: ipê amarelo (Handroanthus chrysotrichus), tanchagem (Plantago australis), picão branco (Galinsoga parviflora), azedinha (Oxalis latifolia), nabo forrageiro (Raphanus sativus), costela de adão (Monstera deliciosa), buva (Conyza bonariensis), serralha (Sonchus oleraceus), caruru (Amaranthus deflexus), alface selvagem (Lactuca serriola), dente de leão (Taraxacum officinale), major gomes (Talinum paniculatum) e capuchinha (Tropaeolum majus). O levantamento das PANCs demonstrou a existência de ampla diversidade de plantas com potencial alimentício negligenciado, desconhecido ou subutilizado, com significativo valor nutricional e cultural, versatilidade de usos e potencial econômico.

Palavras-chave: Alimentação. Diversidade. Desenvolvimento Sustentável.

\section{Abstract}

Several plants are considered invasive and even harmful because they occur among cultivated plants or in other places where they are considered inadequate. These plants are controlled with hoes, tractors, trampling and herbicides, aiming their growth inhibition and definitive eradication. However, many of these spontaneous growth plant species

1 Dra.; Ciências e Produção Vegetal; Universidade Federal de Pelotas, UFPEL, Brasil; Atua como líder do grupo de pesquisa do CNPq "Agronomia e Território do Pampa"; Endereço: Universidade Estadual do Rio Grande do Sul, Uergs Unidade Santana do Livramento, RS. Rua Rivadávia Corrêa - lado ímpar; Centro, CEP: 97573011 - Sant'Ana do Livramento, RS - Brasil; E-mail: simoneterra@yahoo.com.br (*) Autor para correspondências

2 Bolsista de Iniciação Científica da FAPERGS, Edital PROOPG 13/2016. Curso de Bacharelado em Agronomia. Universidade Estadual do Rio Grande do Sul, Santana do Livramento, RS, Brasil. E-mail: rodriguescarla835@gmail.com

\begin{tabular}{llllll}
\hline Ambiência & Guarapuava (PR) & v.l5 n.l & P. II2 - 130 & Jan/Abr 2019 & ISSN I808 - 025I
\end{tabular}


have cultural, ecological and economic importance, some of which may be considered as food. The research aim was to survey UFPs that occur spontaneously in municipality Santana do Livramento (RS) urban perimeter. A bibliographical survey was carried out in main Rio Grande do Sul UFPs, concomitantly with walks in the municipality urban area, contemplating vacant lots, sidewalks, roads and a municipal park, aiming the identification, collection and botanical survey of UFPs with highest occurrence. Thirteen UFPs were collected and identified: yellow ipe (Handroanthus chrysotrichus), mexican plantain (Plantago australis), eclipta (Galinsoga parviflora), fishtail oxalis (Oxalis latifolia), radish (Raphanus sativus), fruit salad plant (Monstera deliciosa), bull thistle (Conyza bonariensis), spiny sowthistle (Sonchus oleraceus), low amaranth (Amaranthus deflexus), prickly lettuce (Lactuca serriola), wild marigold (Taraxacum officinale), ginseng java (Talinum paniculatum) and garden nasturtium (Tropaeolum majus). UFPs survey showed a wide diversity of plants with neglected, unknown or underutilized food potential, with significant nutritional and cultural value, versatility of uses and economic potential.

Keywords: Food. Diversity. Sustainable Development.

\section{Introdução}

$\mathrm{Na}$ agricultura intensiva, o manejo convencional implica erradicação da população de plantas que ocorrem de maneira espontânea nos locais de cultivo, sendo estas também consideradas invasoras, daninhas ou inços. A presença de espécies vegetais espontâneas que dificultam o manejo do solo, leva os agricultores, em alguns casos, a adotar as queimadas, capinas mecânicas ou químicas, que podem gerar intensa degradação do solo. Na prática, o manejo usual parte da premissa que plantas espontâneas são sempre prejudiciais à cultura comercial e, por isso, devem ser eliminadas, sendo intensamente utilizada a capina química como método de controle usual. Cabe ressaltar que, entre os agrotóxicos comercializados mundialmente, os herbicidas correspondem à maior parcela (SPADOTTO et al., 2014).

Entretanto, muitas dessas são espécies que possuem importância cultural, ecológica e econômica, podendo algumas serem consideradas como alimentícias, mesmo com pouca utilização pela maioria da população. Pesquisas desenvolvidas por Kinupp (2007) confrontam as denominações pejorativas de algumas plantas espontâneas e ruderais como daninhas e outras abordagens reducionistas, mostrando suas utilidades e potencialidades econômicas, muitas desconhecidas ou simplesmente esquecidas. Como denominação geral para plantas comestíveis de pouco conhecimento pela sociedade, utiliza-se o termo Plantas Alimentícias Não Convencionais (PANCs).

De acordo com Kinupp e Barros (2007), as plantas alimentícias não convencionais são aquelas que possuem uma ou mais partes ou produtos que podem ser utilizados na alimentação humana, tais como: raízes, tubérculos, bulbos, rizomas, talos, folhas, brotos, flores, frutos e sementes ou ainda látex, resina e goma, ou que são usadas para obtenção de óleos e gorduras comestíveis. Ainda de acordo com os mesmos autores, no conceito de PANCs, incluem-se, também, as especiarias, espécies condimentares e aromáticas, assim como plantas que são utilizadas como substitutas do sal, como edulcorantes, amaciantes de carnes, corantes alimentares e no fabrico de bebidas, tonificantes e infusões. 
Como exemplos de algumas PANCs, consideradas plantas daninhas ou inços, temos o caruru (Amaranthus deflexus L.), a beldroega (Portulaca oleracea L.), o picão preto (Bidens pilosa L.), a serralha (Sonchus oleraceus Wall.), o dente-de-leão (Taraxacum officinale (L.) Webber ex F. H. Wigg), a Maria gorda (Talinum paniculatum (Jacq.) Gaertn.), a urtiga brava (Urtica dioica L.), o trevo ou azedinha (Oxalis latofolia Kunth), Taboa (Typha domingensis L.), o nabo forrageiro selvagem (Raphanus sativus L.), o picão branco (Galinsoga parviflora Cav.), a língua de vaca (Rumex crispux L.), entre outras.

Algumas PANCs apresentam teores nutricionais iguais ou superiores aos encontrados nas hortaliças, raízes e frutos popularmente utilizados na alimentação cotidiana das famílias brasileiras. Especialmente quando se trata de hortaliças e frutas silvestres, geralmente os teores minerais são significativamente maiores do que em plantas domesticadas (FLYMAN; AFOLAYAN,2006). Além dos minerais, em geral, as espécies vegetais não convencionais são mais ricas em fibras e compostos com funções antioxidantes (SCHMEDA-HIRSCHMANN et al., 2005; ODHAV,2007) e muitas são fontes de proteínas superiores às fontes vegetais convencionais (ALETOR et al., 2002).

O desconhecimento sobre a utilidade e forma de uso da maioria das espécies vegetais, associado às tendências contemporâneas de homogeneização da alimentação humana, resultou na redução ou completa supressão da utilização de muitas plantas que faziam parte do cotidiano alimentar dos índios e, posteriormente, dos moradores de zonas rurais e periferias urbanas do Brasil.

Culturalmente, nossa alimentação é baseada em uma ínfima parcela de alimentos. Estimativas apontam que 103 espécies seriam responsáveis por 90\% dos alimentos consumidos no planeta, mas, dentre estas vinte ou trinta espécies são comumente mencionadas (WALTER, 2005). De acordo com o mesmo autor, os alimentos são produzidos com um número cada vez menor de espécies e variedades de plantas, e apenas oito delas: trigo, arroz, milho, batata, mandioca, batata-doce, soja e cevada, por exemplo, estão presentes na maioria dos produtos alimentícios industrializados.

Por outro lado, existe uma oferta potencial de alimentos de pelo menos 30 mil plantas diferentes. Acredita-se que $75 \%$ das variedades tradicionais de plantas alimentícias já foram perdidas e estima-se que, em nossa flora nativa, existam cerca de 4 a 5 mil espécies de plantas com potencial alimentício, porém consome-se como alimento cerca de $20 \%$ dessa flora (LUIS, 2010).

Uma listagem de todas as plantas comestíveis do mundo não existe. Numa das relações mais completas, são enumeradas cerca de 12.500 espécies potencialmente alimentícias, perfazendo 3.100 gêneros e cerca de 400 famílias, em sua maioria angiospermas (KUNKEL, 1984).

As hortaliças normalmente consumidas pela população, como a couve, a cenoura e a batata, possuem tratos culturais específicos durante o seu ciclo produtivo; porém apreciam solos férteis, com irrigação periódica e luz solar abundante (FILGUEIRA, 2013). Muitas PANCs, contudo, adaptam-se a necessidades diferentes, podendo ocupar espaços onde há pouca insolação, cujo solo não seja tão fértil, ou úmido, ou seco demais para as culturas convencionais (RANIERI, 2017).

Uma alimentação diversa e variada traz todos os nutrientes que o organismo humano precisa, e as PANCs são um caminho para uma alimentação adequada, saudável e responsável (BORGES; SILVA, 2018).

Algumas plantas espontâneas têm sido tão importantes que, hoje, fazem parte de sistemas de produção, como por exemplo, o trevo branco (Trifolium repens Lam.) e o azevém (Lolium multiflorum L.). Foi assim também com outras espontâneas, hoje consagradas, cultivadas e 
consumidas em todo o mundo, como ervilha (Pisum sativum L.), mostarda (Brassica campestres L.), aveia (Avena sativa L.) e centeio (Secale seraele L.), espécies que, inicialmente, eram consideradas invasoras, mas, logo que se percebeu seu valor alimentício, tornaram-se cultivos comerciais (HARLAN, 1955).

As PANCs devem estar relacionadas com aquilo que o ambiente local pode proporcionar. De acordo com Pinheiro (2000), é interessante para o desenvolvimento regional, maximizar aquilo que pode ser produzido num determinado território. Todas as regiões do país possuem grande potencial para explorar plantas alimentícias não convencionais, sejam elas nativas ou naturalizadas (RANIERI, 2017).

A maioria das espécies de PANCs são adaptáveis a diversos ambientes, germinando em meio às hortas abandonadas, quintais, terrenos baldios e calçadas. Assim, as PANCs não precisam necessariamente ser cultivadas, e sim mantidas e manejadas de acordo com as condições de solo e interesse em sua manutenção e propagação.

As PANCs, quando cultivadas pelos agricultores, podem auxiliar no aproveitamento de áreas antes improdutivas, por possuírem exigências sazonais distintas, agregando uma oferta maior de alimentos ao longo do ano. Ao optar por espécies vegetais mais resistentes às condições ambientais locais, essa oferta pode ser menos afetada por excesso de chuvas ou por ondas de calor ou frio (CHOMENKO, 2016).

Vale ressaltar que uma planta pode ser convencional em uma determinada região, pois já está incorporada no hábito alimentar local, e ser considerada PANC em outra. Um exemplo é a espécie ora pró nobis (Pereskia aculeata Mill.) desconhecida, por exemplo, da maioria das pessoas da cidade de São Paulo, mas muito consumida em algumas regiões do interior de Minas Gerais e Rio de Janeiro (ALMEIDA; CORRÊA, 2012).

Podem-se considerar como PANCs algumas plantas comumente consumidas, como a batata doce (Ipomoea batatas), da qual, normalmente, consome-se somente o tubérculo, descartando-se o restante (folhas e caule), sendo que eles também podem ser consumidos por humanos. Portanto, as plantas alimentícias não conhecidas pela maioria das pessoas e as partes não usuais de plantas conhecidas podem ser classificadas como PANCs (KINUPP; LORENZI, 2014).

O tema PANCs ainda é negligenciado por grande parte da população, pelo poder público e pelos órgãos de pesquisa, mas atualmente começa a ter alguma divulgação para o grande público, possivelmente em função da demanda por uma alimentação mais natural, orgânica e sem agrotóxicos. Essas plantas possuem potencial para complementar a alimentação das pessoas, diversificar cardápios e nutrientes consumidos e, até mesmo, consistirem em fontes adicionais de renda, através da venda das partes das plantas ou de produtos como geleias, farinhas e outros (ERICE, 2011).

Com o crescimento das cidades, das monoculturas e da consequente contaminação do ambiente natural pelos agroquímicos, as dificuldades de se encontrarem alimentos isentos de agrotóxicos e as distâncias para colhê-los, torna-se um obstáculo para a população que almejam a segurança alimentar. Assim, terrenos baldios, quintais e muros vivos vegetais podem ser aproveitados para a obtenção de fontes complementares de alimentos não convencionais, seja através do extrativismo de plantas espontâneas, seja pelo manejo e cultivo destas espécies adaptadas. Sacadas de apartamentos também podem ser aproveitadas para o cultivo de plantas alimentícias. O paisagismo também poderia ser repensado, evitando-se plantas tóxicas e priorizando as plantas com estética e, também, possibilidade de uso alimentício, o chamado Paisagismo Comestível (RANIERI, 2017), que é a conjugação de plantas de finalidade alimentícia com potencial ornamental. Nessa categoria estão, por exemplo, a capuchinha, a major gomes, o peixinho, a celósia e o lírio amarelo.

Entretanto, a falta de informações sobre estas plantas contribui para o não uso e até mesmo para o desaparecimento delas (MAPA, 2010). O incentivo ao consumo das PANCs, 
além de assegurar sua proteção, por serem restritas a determinadas localidades ou regiões, pode contribuir para a soberania e a segurança alimentar e nutricional da população humana, pois são alimentos acessíveis e de baixo custo em comparação com hortaliças convencionais, além de algumas apresentarem alto valor nutricional (KINUPP; BARROS, 2008).

Santana do Livramento, município localizado na Fronteira Oeste do Rio Grande Do Sul, caracteriza-se pelo baixo consumo de hortaliças e frutas em relação às outras regiões do Estado, possivelmente por influência das culturas uruguaia e gaúcha, que possuem preferências naturais e históricas pela carne bovina como principal alimento nas refeições diárias. Estudos realizados por Farias et al. (2014) revelam que apenas $1 / 3$ dos consumidores da fronteira do Rio Grande do Sul com a Argentina e com Uruguai possuem o hábito de consumir frutas e hortaliças diariamente, sendo maior o consumo pelas mulheres do que pelos homens.

Porém, atualmente esse cenário vem mudando e o município começa a construir um histórico no consumo e na produção local de hortaliças, inclusive orgânicas, possivelmente impulsionado pela crescente demanda da sociedade por um estilo de vida mais saudável e isenta de adubos químicos e agrotóxicos. Pesquisas de TERRA e DA COSTA (2017) apontam que os consumidores de hortaliças em Santana do Livramento, com idade entre 46 e 55 anos e com nível superior de escolaridade, preferem olerícolas cultivadas em sistema orgânico de produção, motivados, principalmente, pela ausência da aplicação de agrotóxicos.

Assim, o levantamento de PANCs na zona urbana no município, pode constituir um incentivo para que a população santanense conheça opções de baixo custo para complementar a alimentação diária, de creches ou de escolas e, até mesmo, uma nova forma de utilização dos espaços ociosos das cidades, pelo cultivo de hortas urbanas consorciadas com PANCs.

No Brasil, existe escassez de trabalhos científicos, e mesmo de divulgação, abordando a temática das plantas alimentícias não convencionais. Nesse contexto, e pela ausência de literaturas sobre o tema na região da Fronteira Oeste do RS, ressalta-se a importância de um levantamento sobre as PANCs que surgem espontaneamente no perímetro urbano de Santana do Livramento.

\section{Material e Métodos}

O trabalho de identificação botânica e levantamento bibliográfico das PANCs foi executado na Universidade Estadual do Rio Grande do Sul, Uergs, no Campus Central de Santana do Livramento, RS, entre junho de 2017 e junho de 2018. A coleta das espécies vegetais foi realizada em saídas de campo, em ruas da zona urbana e em um parque municipal, no mesmo período.

Santana do Livramento (Latitude: 30 53' 27” S / Longitude: 55 31' 58” W) caracterizase por apresentar clima quente e temperado, com temperatura média de $18,4{ }^{\circ} \mathrm{C}$ e pluviosidade média anual de $1.467 \mathrm{~mm}$. A classificação do clima é Cfa segundo a classificação de Köppen e Geiger (1928).

Inicialmente, foi realizado levantamento bibliográfico sobre as principais plantas alimentícias não convencionais de ocorrência no Rio Grande do Sul, utilizando como fontes artigos científicos, teses e dissertações obtidas através do Google acadêmico, plataforma Scielo, além do acervo bibliográfico da Uergs. Foram selecionados os trabalhos que permitiram obter informações sobre a origem e descrição botânica, ecologia, propriedades alimentares, composição química, utilizações, características culturais e importância alimentar. 
Concomitantemente ao levantamento bibliográfico, foram efetuadas duas saídas de campo na zona urbana do município, contemplando um parque municipal (Parque Municipal do Lago do Batuva), terrenos baldios e acostamentos de ruas previamente determinadas (ruas Sete de Setembro e Senador Salgado Filho), visando à identificação, à coleta e ao levantamento das PANCs de maior ocorrência no município.

Os terrenos baldios e ruas para o levantamento e coleta de plantas foram definidos de acordo com a disponibilidade vegetal na época e a localização no entorno da sede central da Uergs, evitando os que continham animais, lixo em abundância e objetos que pudessem ser impedimentos físicos para a coleta.

A primeira atividade de campo foi realizada no dia 12 de setembro de 2017, com destino ao Parque Municipal do Lago do Batuva, situado a 4,3 Km do centro do município de Santana do Livramento.

A segunda atividade de campo foi realizada no dia 31 de outubro de 2017, nas ruas Sete de Setembro e a Senador Salgado Filho, locais com elevada disponibilidade de plantas espontâneas consideradas PANCs.

Para a identificação vegetal, foi utilizada bibliografia específica para famílias, gêneros e espécies, através de chaves de identificação (APG IV, 2016), além de consulta aos herbários didáticos disponíveis na Uergs. Também utilizou-se da observação visual comparativa auxiliada pelo livro "Plantas Alimentícias Não Convencionais (PANC) no Brasil: guia de identificação, aspectos nutricionais e receitas ilustradas" (KINUPP; LORENZI, 2014).

Para a identificação botânica, as PANCs foram fotografadas com máquina digital, coletadas com auxílio de tesoura e estilete, etiquetadas e armazenadas em sacolas plásticas para posterior secagem e confecção das exsicatas botânicas, que são plantas secas e prensadas, fixadas em folha de papel, acompanhadas de uma etiqueta de informações sobre o vegetal, para fins de estudos botânicos através da confecção de um herbário didático.

No processo de secagem e prensagem para obtenção das exsicatas foi utilizada uma prensa de madeira, onde foram adicionadas camadas de jornais entre as plantas, objetivando a absorção da umidade das partes vegetais. Os jornais foram trocados semanalmente, para que não houvesse contaminação por fungos no material coletado.

\section{Resultados e Discussões}

A primeira coleta de campo foi realizada no Parque Municipal do Lago do Batuva (Figura 1), local inserido no Bioma Pampa que, segundo Chomenko et al. (2016), é caracterizado por ser um vasto espaço geográfico onde as árvores limitam-se a formar uma moldura ao longo dos cursos d'água ou estão confinadas às áreas de relevo mais acidentado. Os mesmos autores citam que o Bioma Pampa é constituído por ervas do tipo gramíneas e outras plantas rasteiras perfeitamente adaptadas às condições climáticas e aos solos da região, formando um complexo sistema de campos naturais. Em função das características naturais, o Parque Municipal do Lago do Batuva, que está inserido no Bioma Pampa, proporcionou a coleta de PANCs de porte herbáceo e arbustivo. 
Figura 1. Paisagem característica do Parque Municipal do Lago do Batuva, local da primeira coleta de PANCS, na zona urbana de Santana do Livramento, RS, Brasil.

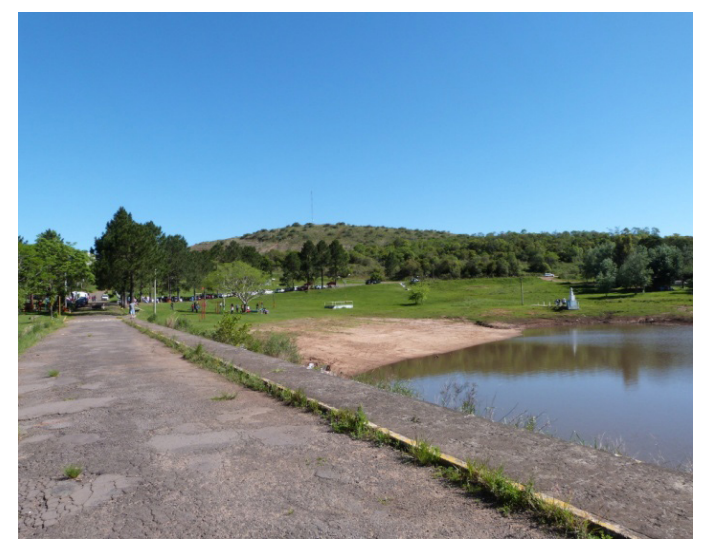

Fonte: Uergs, 2017 (Foto do acervo pessoal das autoras).

Foram coletadas e identificadas cinco espécies vegetais que são consideradas como alimentícias não convencionais: ipê amarelo (Handroanthus chrysotrichus) (Figura 2), tanchagem (Plantago australis) (Figura 3), picão branco (Galinsoga parviflora) (Figura 4), azedinha (Oxalis latifolia) (Figura 5) e nabo forrageiro (Raphanus satious) (Figura 6).

O ipê amarelo, espécie pertencente à família Bignoniaceae, é também conhecida comumente como ipê amarelo cascudo, ipê do morro e pau d'arco amarelo (BIAGOLINI,2016). Possui flores amarelas consideradas comestíveis, podendo ser ingeridas cruas em saladas ou preparadas na forma empanada e frita, possuindo sabor levemente amargo, similar à alface ou almeirão, podendo serem utilizadas como entradas, em confraternizações e até mesmo restaurantes de alta gastronomia (KINUPP; LORENZI, 2014).

Figura 2. Flores e vagens de ipê amarelo (Handroanthus chrysotrichus) presentes no Parque Municipal do Lago do Batuva, Santana do Livramento, RS, Brasil.

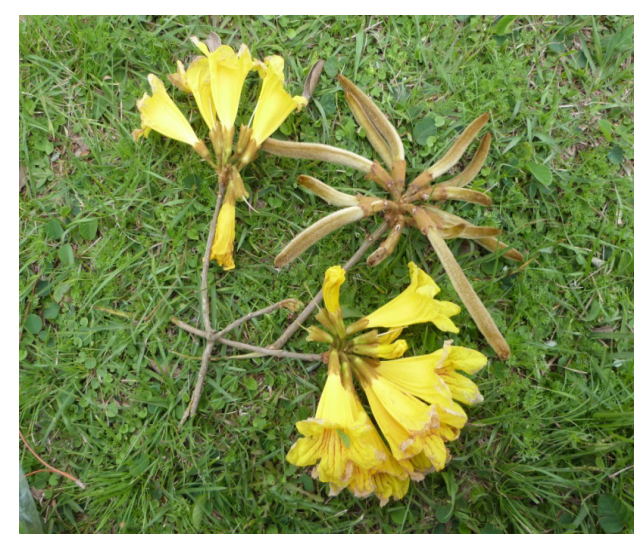

Fonte: Uergs, 2017 (Foto do acervo pessoal das autoras). 
A tanchagem (Plantago australis) é uma espécie herbácea perene, com caule em roseta, nativa do Sul e Sudeste do Brasil e muito frequente em áreas antropizadas, como em pomares, hortas, jardins e solos agrícolas em geral, principalmente se parcialmente sombreadas, chegando a ser considerada planta daninha em vários locais (ERICE, 2011).

Pertencente à família Plantaginaceae, a tanchagem também é conhecida como transagem, língua de vaca, cinco nervos, bopka e llanten. A propagação ocorre principalmente por sementes, que podem também ser consumidas in natura.Já as folhas podem ser consumidas após o cozimento e preparo culinário apropriado, sendo as jovens empregadas na confecção de bolinhos fritos, podendo ainda ser empanadas em pedaços e utilizadas no fabrico de pães e bolos. Além disso, a tanchagem é empregada para fins medicinais, especialmente como cicatrizante e anti-inflamatório (CARNEIRO, 2004).

\section{Figura 3. Tanchagem (Plantago australis) presente no Parque Municipal do Lago do Batuva, Santana do Livramento, RS, Brasil}

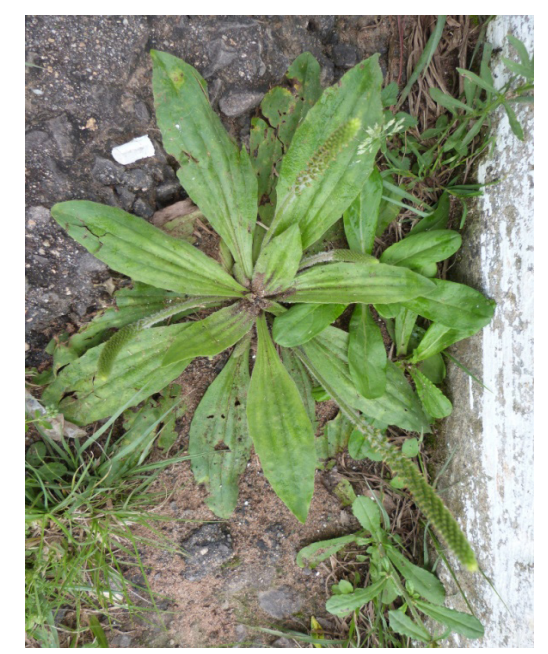

Fonte: Uergs, 2017 (Foto do acervo pessoal das autoras).

O picão branco (Galinsoga parviflora) apresenta folhas simples, opostas, sendo as inferiores pecioladas e as superiores praticamente sésseis, com limbo flácido de formato ovalado a oblongo e de margens crenadas ou levemente serreadas e ápice agudo (KISSMANN; GROTH, 1999). Informações de Moreira e Bragança (2011) citam que o picão branco é uma espécie herbácea anual que se desenvolve nas Regiões Sudeste e Sul do país, onde se instala em áreas cultivadas, passando a competir por espaço. Ocorre com muita frequência em áreas olerícolas com cultivos de alho, batata, beterraba, cebola, cenoura, couve-flor e tomate, entre outras. Ocorre ainda em pomares de laranja e goiaba, quadras de maracujá e nos cultivos de banana e uva. 
Figura 4. Picão branco (Galinsoga parviflora) presente no Parque Municipal do Lago do Batuva, Santana do Livramento, RS, Brasil.

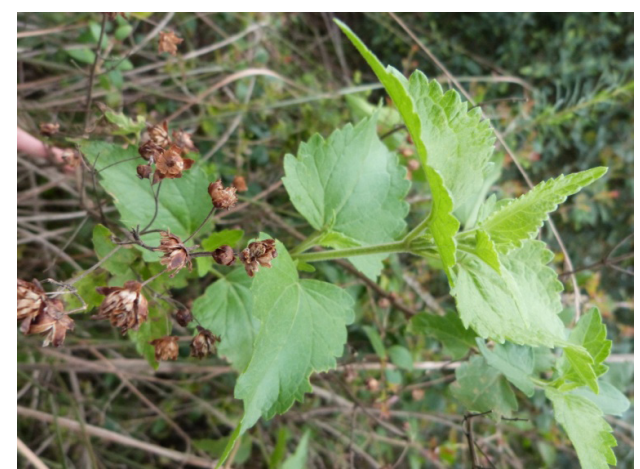

Fonte: Uergs, 2017 (Foto do acervo pessoal das autoras).

As folhas do picão branco são amplamente utilizadas na culinária como tempero, principalmente nos países andinos (Colômbia e Peru) onde é industrializada com o nome de 'guasca' (nome local da planta). No Brasil, também pode ser empregada desta forma, como também na forma de saladas cruas. A parte aérea jovem (folhas, ramos e flores) pode ser consumida crua ou também cozida; em copas, misturada a farofas ou utilizada no preparo de bolinhos fritos e em sucos verdes com limão ou frutas ácidas (KINUPP; LORENZI, 2014).

Outra PANC identificada no primeiro local de coleta foi a azedinha (Oxalis latifolia), que se caracteriza pelas flores de cor rosa, bulbo arredondado, folíolos de ápice truncado com os lóbulos divergentes (GRIGOLETTO, 2013). Seu hábitat são áreas abertas, alteradas e ensolaradas como terrenos cultivados, hortas, canteiros, beira de caminhos e estradas.

\section{Figura 5. Azedinha (Oxalis latifolia) presente no Parque Municipal do Lago do Batuva, Santana do Livramento, RS, Brasil.}

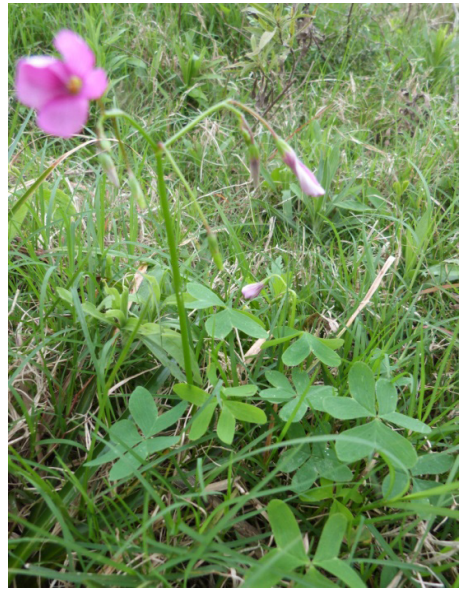

Fonte: Uergs, 2017 (Foto do acervo pessoal das autoras). 
A família à qual a espécie azedinha pertence é a Oxalidaceae e alguns dos nomes comuns que ela recebe são trevinho, trevo azedo, trevo e azedinha de folha cortada. Toda a parte aérea da planta pode ser consumida, tanto crua como após o cozimento e outros preparos culinários (KINUPP; LORENZI, 2014). Recomenda-se cautela no consumo das espécies do gênero, pois assim como o espinafre e o ruibarbo, muitas outras espécies Oxalis spp. são ricas em ácido oxálico, que pode causar problemas renais se consumido em excesso (GRIGOLETTO, 2013).

A última espécie coletada no ao Parque Municipal do Lago do Batuva foi o nabo forrageiro (Raphanus sativus), pertencente à família Brassicaceae.

\section{Figura 6. Nabo forrageiro (Raphanus sativus) presente no Parque Municipal do Lago do Batuva, Santana do Livramento, RS, Brasil.}

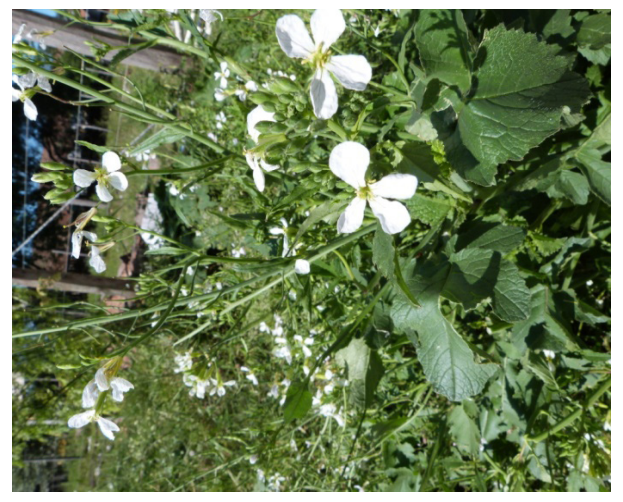

Fonte: Uergs, 2017 (Foto do acervo pessoal das autoras).

O nabo forrageiro apresenta caule cilíndrico, bastante ramificado, ceroso e com esparsa pilosidade, folhas alternadas, pecioladas e com o limbo profundamente recortado em até 9 segmentos, os quais chegam à nervura central ou próximo, simulando folha composta (MOREIRA; BRAGANÇA, 2011). A propagação é realizada por meio de sementes, sendo essa PANC também conhecida popularmente como rabanete silvestre, rábano, nabo chinês e nabiça selvagem.

De acordo com Giraldi (2007), as folhas jovens do nabo forrageiro podem ser refogadas, ensopadas, utilizadas cruas na salada ou na confecção de bolinhos fritos. As flores frescas, devido a sua beleza, são indicadas para decoração comestível de pratos doces ou salgados, podendo ainda serem salteadas ou cozidas. Os frutos bem tenros podem ser salteados e servidos puros ou com carnes, ovos, peixes e usados para conservas (picles). Além disso, as sementes produzem óleo alimentício e quando germinadas produzem brotos picantes, que podem ser desidratados, moídos e usados como sal vegetal.

Concomitantemente à identificação das PANCs, foram coletados exemplares vegetais para a confecção das exsicatas (Figura 7) componentes do herbário didático. O processo de secagem para a organização das exsicatas das espécies vegetais coletadas é de extrema importância, a fim de evitar a destruição da planta durante o processo. Dessa forma, é possível a manutenção das características botânicas dos materiais coletados, possibilitando a consulta em estudos acadêmicos futuros. 


\section{Figura 7. Planta de ipê amarelo recém coletada para a produção de exsicata componente de herbário didático.}

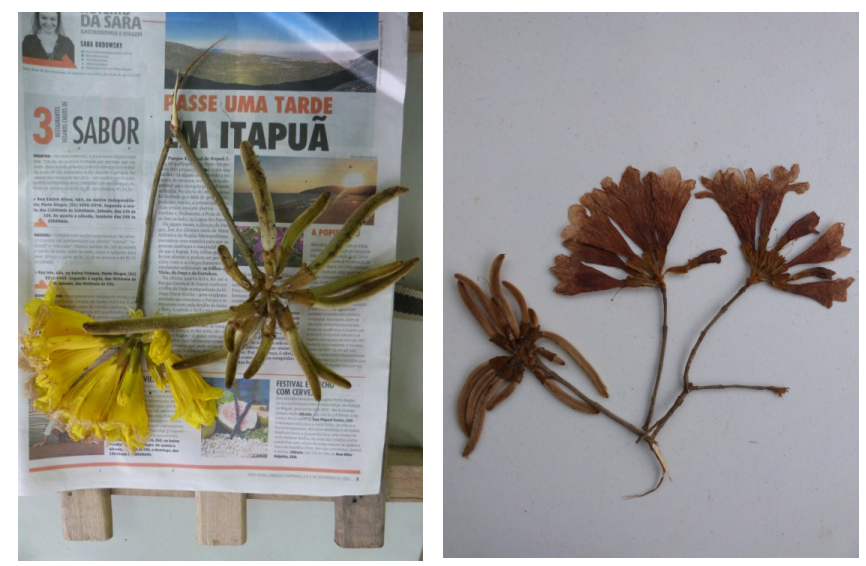

Fonte: Uergs, 2017 (Foto do acervo pessoal das autoras).

Ao final da primeira coleta, percebeu-se que, como o Parque Municipal do Lago do Batuva é considerado local turístico e de lazer para a população de Santana do Livramento, com intensa movimentação de pessoas aos finais de semana, frequentemente são realizadas roçadas mecânicas pela Prefeitura Municipal, o que explica a inexistência de muitas espécies vegetais consideradas PANCs, na ocasião da coleta.

A segunda coleta de campo foi realizada em ruas da zona urbana do município, de acordo com os critérios anteriormente descritos.

$\mathrm{Na}$ ocasião, foram coletadas e identificadas quatro plantas espontâneas consideradas como alimentícias não convencionais pela literatura, sendo: costela de adão (Monstera deliciosa) (Figura 8), buva (Conyza bonariensis) (Figura 9), serralha (Sonchus oleraceus) (Figura10) e alface selvagem (Lactuca serriola) (Figura 11).

A costela de adão (Monstera deliciosa), de acordo com Peppard (1992) apud Barros (2012), é uma planta tropical, nativa da América Central (México), tendo sido difundida para a Flórida, Portugal, Argélia e Austrália. É conhecida como pinha-anona no México, arpão na Guatemala, ceriman em Inglaterra e costela de Adão, banana de brejo, banana de macaco, banana do mato ou fruta do México em Portugal (JANICK; PAULL, 2008).

De acordo com Peters e Lee (1997) apud Barros (2012), a costela de Adão é geralmente utilizada como planta decorativa, podendo desenvolver-se bem em vasos, no interior de habitações. A costela de Adão é uma planta trepadeira pertencente à família Araceae, possuindo as margens das folhas dotadas de recortes e perto da nervura central encontram-se orifícios de vários tamanhos (JANICK; PAULL, 2008 apud BARROS, 2012).

As folhas do exemplar da costela de Adão, coletadas durante a pesquisa, apresentavam entre 70 a $90 \mathrm{~cm}$ de comprimento e entre 60 a $80 \mathrm{~cm}$ de largura, concordando com os dados pesquisados por Barros (2012), cujas folhas atingiram $90 \mathrm{~cm}$ de comprimento e $80 \mathrm{~cm}$ de largura. 


\section{Figura 8. Costela de Adão (Monstera deliciosa) presente em ruas da zona urbana de Santana do Livramento, RS, Brasil.}

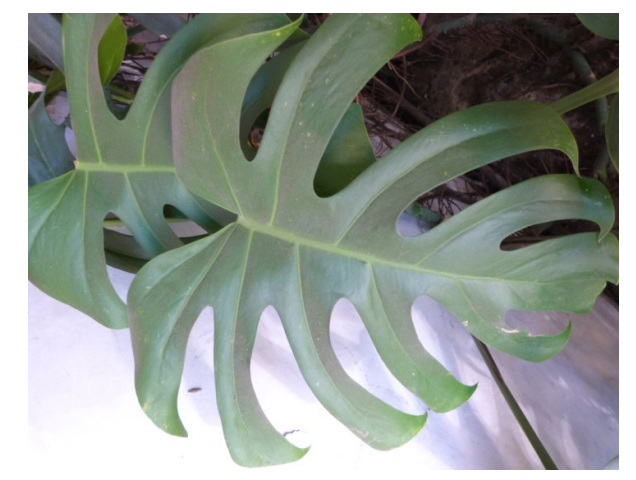

Fonte: Uergs, 2017 (Foto do acervo pessoal das autoras).

O fruto da Monstera deliciosa é descrito como uma pinha de forma alongada, com comprimento situado entre os 20 e $30 \mathrm{~cm}$ e um diâmetro de 5 a $9 \mathrm{~cm}$, de coloração verde e casca constituída por pequenas plaquetas de forma hexagonal (GOULD; HALLMAN, 2001; PEPPARD,1992 apud BARROS, 2012), que caem gradualmente à medida que o fruto amadurece.

Quando o fruto da Monstera deliciosa se encontra completamente maduro, desenvolve-se um aroma delicado a ananás e banana. $\mathrm{O}$ fruto é extremamente doce, no entanto, quando não se encontra completamente maduro, oferece uma sensação de irritação na boca, provavelmente causada pela presença de cristais de oxalato de cálcio (PEPPARD, 1992 apud BARROS, 2012).O fruto pode ser consumido quando as plaquetas se encontram soltas, sendo a polpa madura servida geralmente como sobremesa juntamente com chantilly, saladas ou sumos de fruta (PETERS; LEE, 1977 apud BARROS, 2012).

A buva (Conyza bonariensis), também conhecida como erva lanceta, é uma espécie anual, herbácea e ereta, de caules densamente folhosos, que se propaga por sementes. É considerada uma importante planta invasora dos campos de cultivo de soja no RS. Os frutos são denominados aquênios que possuem uma estrutura denominada papilho piloso, o qual facilita sua dispersão pelo vento (BRIGHENTI et al., 2010).

\section{Figura 9. Buva (Conyza bonariensis) presente em ruas da zona urbana de Santana do Livramento, RS, Brasil.}

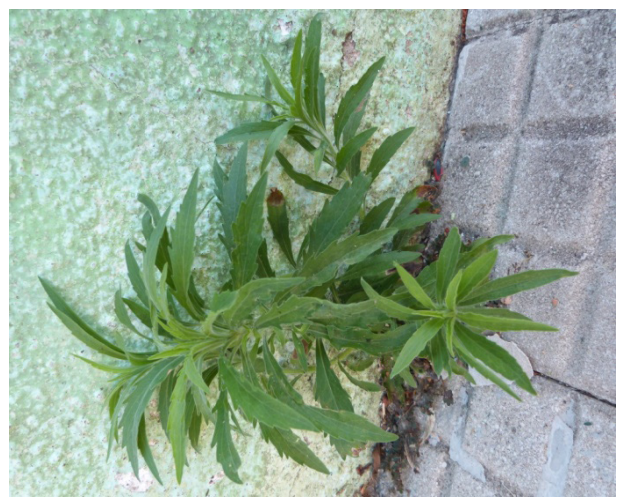

Fonte: Uergs, 2017 (Foto do acervo pessoal das autoras). 
Essa espécie pode ser facilmente reconhecida em campo pelas folhas longo-lanceoladas e com margem inteira, acrescentando-se ainda a posição da inflorescência, que é sempre inclusa aos ramos, e também pelos capítulos globosos (BRIGHENTI et al., 2003).

De acordo com Kelen et al. (2015), as folhas e ramos foliares novos da buva são comestíveis, sendo aromáticos e ligeiramente picantes. As partes da planta podem ser utilizadas como condimento de carnes e outros ou consumidas como saladas cruas, cozidas e ensopados.

A serralha (Sonchus oleraceus) é uma espécie anual, herbácea, lactescente, ereta, glabra, pouco ramificada, de 40-110 cm de altura. É originária possivelmente do Continente Europeu, porém encontrada em mais de 60 países do mundo (LORENZI, 2000).

\section{Figura 10. Serralha (Sonchus oleraceus) presente em ruas da zona urbana de Santana do Livramento, RS, Brasil.}

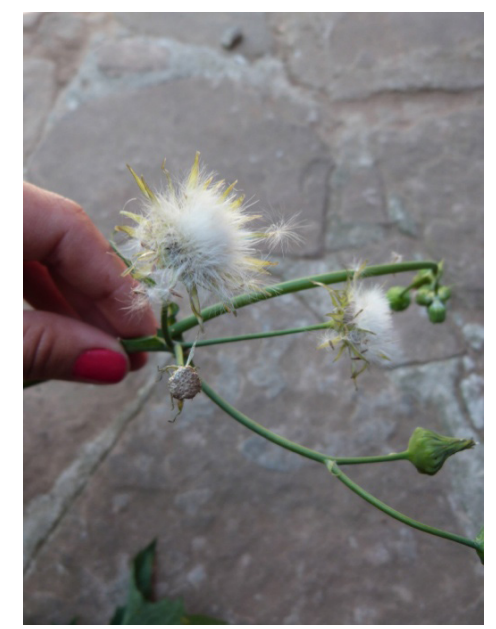

Fonte: Uergs, 2017 (Foto do acervo pessoal das autoras).

O caule da serralha caracteriza-se como carnoso e produz látex. As folhas são simples e muito irregulares. Todas as margens das folhas apresentam pequenos dentes pontiagudos moles. A superfície é glabra, lisa e lustrosa, de cor verde-escura. Sua raiz principal é pivotante e as secundárias bastante fibrosas (BRIGHENTI et al., 2010). Propaga-se exclusivamente por meio de sementes. Uma única planta pode produzir cerca de 100.000 sementes e a germinação no solo se dá na superfície ou até $2 \mathrm{~cm}$ de profundidade (KISSMANN; GROTH, 1999).

Conforme afirmado por Kelen (2015), as folhas da serralha são comestíveis e utilizadas na forma crua, em saladas, ou cozidas, como acompanhamento de carnes. De acordo com Kinupp e Lorenzi (2014), pode ocorrer o consumo de toda a parte aérea das plantas jovens (folhas, talos tenros e até as flores - capítulos - bem jovens). As flores e botões podem ser feitos à milanesa, já os caules (talos) podem ser usados para conservas.

A alface selvagem (Lactuca serriola) é pertencente à família Asteraceae, sendo uma planta selvagem encontrada originalmente na Ásia, Europa e África, de folhas espinhosas e estreitas e de coloração verde escura, que foi posteriormente utilizada na geração de algumas variedades modernas de alface (LORENZ, 1992; PINK; KEANE, 1993). 


\section{Figura 11. Alface selvagem (Lactuca serriola) presente em ruas da zona urbana de Santana do Livramento, RS, Brasil.}

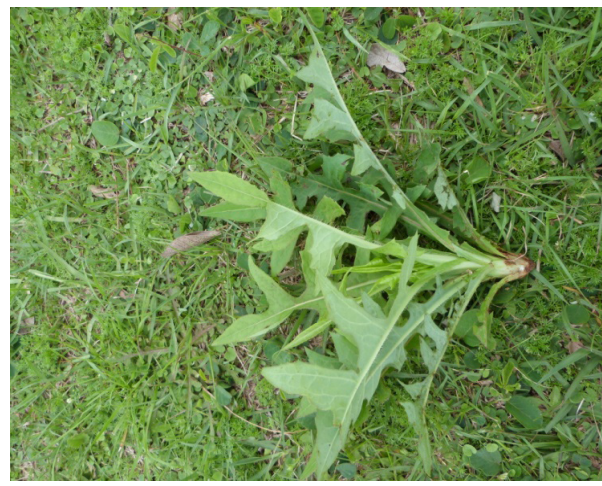

Fonte: Uergs, 2017 (Foto do acervo pessoal das autoras).

Ryder (1999) apud Suinaga (2013) demonstrou que, provavelmente, a alface comercial evoluiu até o fenótipo atual por meio de seleções e mutações originárias da espécie silvestre Lactuca serriola L., que era utilizada como cultura forrageira e oleaginosa. Mou (2008) atesta que o cultivo de formas ancestrais de alface ocorreu Egito, onde era utilizado o suco leitoso (látex) da planta como substância sonífera. A partir de sua domesticação, a alface foi disseminada pela região do Mediterrâneo, nas eras Grega e Romana e, a partir dessa região, para o resto do continente europeu. Citações apontam que foram os romanos que desenvolveram a alface de folha larga, atualmente consumida, com pouco látex, sem espinhos e de germinação uniforme (NONNECKE, 1989; PHILLIPS; RIX, 1993).

A alface selvagem possui diversos nomes comuns, sendo os principais: alface do campo, alface do mato e alface da serra. Suas folhas são consumidas, tanto cruas como após cozimento, podendo ser refogadas, ensopadas, cozidas com arroz, usadas para omeletes, bolinhos e até para pães, já os botões florais (capítulos jovens) podem ser usados no preparo de saladas, refogados e empanados (CARNEIRO, 2004).

Ao término da pesquisa, percebeu-se que o levantamento das PANCs é fundamental para se reconhecerem os aspectos botânicos de cada espécie identificada, como forma de evitar o consumo equivocado e possíveis intoxicações ou efeitos colaterais devido à ingestão de plantas com fatores antinutricionais.

Através dos resultados obtidos, espera-se contribuir para a redução da xenofilia alimentícia, vastamente praticada pela maioria da população brasileira, que consiste na valorização exagerada de espécies exóticas em detrimento de espécies nativas ou espontâneas, mesmo que estas possuam características similares e até superiores às exóticas. A partir desse tipo de informação gerada, pode-se auxiliar na divulgação da valorização local dos recursos alimentares nativos, que não devem ser desprezados em detrimento de recursos exóticos.

\section{Conclusões}

Verifica-se a existência de diversas espécies de plantas alimentícias não convencionais na zona urbana de Santana do Livramento, a partir do levantamento e caracterização botânica das plantas de maior ocorrência nos locais de coleta. A maioria das PANCs identificadas na pesquisa 
possui o hábito de crescimento rasteiro e porte herbáceo, apresentando ciclos de produção anual e perene. As formas de consumo mais citadas na literatura são: refogadas (cozidas) em molhos e caldos, em saladas e in natura.

As principais espécies PANCs identificadas e contabilizadas em maior quantidade no levantamento durante a pesquisa são: ipê amarelo (Handroanthus chrysotrichus), tanchagem (Plantago australis), picão branco (Galinsoga parviflora), azedinha (Oxalis latifolia), nabo forrageiro (Raphanus sativus), costela de adão (Monstera deliciosa), buva (Conyza bonariensis), serralha (Sonchus oleraceus) e alface selvagem (Lactuca serriola).

Como as PANCs têm potencial para complementação alimentar, pode-se pensar em futura divulgação para a comunidade gastronômica, local sobre a diversificação dos cardápios e dos nutrientes ingeridos e também na escolha de novas fontes de renda para a agricultura familiar, como a venda de partes das plantas nas feiras livres ou de produtos processados (geleias, pães, farinha, conservas) e através do turismo, rural ou gastronômico. Também se espera aprofundar o estudo sobre a ocorrência local das PANCs, para que informações confiáveis possam ser divulgadas à população em geral, inclusive para creches e escolas como forma de inclusão de novos sabores à alimentação diária das crianças e dos estudantes.

\section{Referências}

ALETOR, V.A. et al. Chemical composition of common leafy vegetables and functional properties of their leaf protein concentrates. Food Chemistry, v. 78, n. 1, p. 63-68, 2002.

ALMEIDA, M. E. F.; CORRÊA, A. D. Utilização de cactáceas do gênero Pereskia na alimentação humana em um município de Minas Gerais. Ciência Rural, Santa Maria, v. 42, n. 4, p. 751-756, 2012.

APG IV. 2016. An update of the Angiosperm Phylogeny Group classification for the orders and families of flowering plants: APG IV. Botanical Journal of the Linnean Society 181: 1-20.

BARROS,T.I. V. O fruto de Monstera deliciosa: caracterização físico-química e potencial para produção de aguardente. 2012. Dissertação (Mestrado em Tecnologia de Alimentos, Departamento de Engenharia Alimentar, Instituto Superior de Engenharia), Universidade do Algarve, Faro, 2012.

BIAGOLINI, C. H. Quebra de dormência em sementes de ipê amarelo com utilização de água clorada: avaliação do melhor tempo. Revista Científica FAEMA, v. 7, n.2, 2016.

BORGES, C. K. G. D; SILVA, C. C. Plantas alimentícias não convencionais (PANC): a divulgação científica das espécies na cidade de Manaus, AM. Revista Eletrônica Científica Ensino Interdisciplinar, Mossoró, v. 4, n. 11, 2018. 
BRIGHENTI, A. M. et al. Manual de identificação e manejo de plantas daninhas em cultivos de cana-de-açúcar. Juiz de Fora: Embrapa Gado de Leite, 2010. Disponível em: $<$ https://ainfo.cnptia.embrapa.br/digital/bitstream/item/26157/1/Manual-Brighenti.pdf>. Acesso em: 04 dez. 2017.

BRIGHENTI, A. M.; CASTRO, C.; GAZZIERO, D. L. P. Cadastramento Fitossociológico de Plantas daninhas na cultura de Girassol. Pesquisa Agropecuária Brasileira, Brasília, v. 38, n. 5, p. 651-657, 2003.

CARNEIRO, A. M. Espécies ruderais com potencial alimentício em quatro municípios do Rio Grande do Sul. 2004. Tese (Doutorado do Programa de Pós-Graduação em Botânica), Instituto de Biociências, Universidade Federal do Rio Grande do Sul, UFRGS, Porto Alegre, 2004.

CHOMENKO et al. Nosso Pampa desconhecido. Porto Alegre: Fundação Zoobotânica do Rio Grande do Sul, 2016. Disponível em: http://www.fzb.rs.gov.br/ upload/20160429181829nosso_pampa_desconhecido.pdf>. Acesso em: 13 dez. 2017.

ERICE, A. S. Cultivo e comercialização de plantas alimentícias não convencionais (PANCS) em Porto Alegre, RS. 2011. 48 f. Monografia (graduação), Universidade Federal do Rio Grande do Sul, Curso de Ciências Biológicas, 2011.

FARLAS, R. de M.; BARRETO, C. F.; ZANDONÁ, R. R.; ROSADO, J. P.; MARTINS, C. $R$. Comportamento do consumidor de frutas na região da fronteira oeste do Rio Grande Do Sul com Argentina e Uruguai. Revista Brasileira de Fruticultura, vol.36 no. 4 Jaboticabal, 2014

FILGUEIRA, F. A. R. Novo Manual de Olericultura: agrotecnologia moderna na produção e comercialização de hortaliças. 3. ed. rev. ampl. Viçosa: UFV, 2013.

FLYMAN, M. V.; AFOLAYAN, A. J. The suitability of wild vegetables for alleviating human dietary deficiencies. South African Journal of Botany, v. 72, n. 4, p. 492-497, 2006.

GIRALDI, M. Recursos alimentares vegetais em duas comunidades caiçaras no sudeste do Brasil: discutindo modos de vida e segurança alimentar. 2007. Dissertação (Mestrado do Programa de Pós-Graduação em Botânica). Universidade Federal Rural de Pernambuco, Recife, 2007.

GOULD, W. P., E HALLMAN, G.J. Laboratory and field infestation studies on Monstera to determine its host status in relation to the caribbean fruit fly (Diptera: Tephritidae). Florida Entomologist. v. 84, n. 3, p. 437-438. 2001.

GRIGOLETTO, D. O gênero Oxalis (Oxalidaceae) no Rio Grande do Sul, Brasil. 2013. Dissertação (Mestrado do Programa de Pós-Graduação em Agrobiologia, Área de Concentração Agrobiologia) - Universidade Federal de Santa Maria (UFSM, RS), Santa Maria, 2013. 
HARLAN, J. R. Crops, weeds and revolution. The scientific monthly. v. 80, n. 5, p. 299303, 1955.

JANICK, J.; PAULL, R. E. The encyclopedia of fruit \& nuts. CABI. Londres, 2008.

KELEN, M. E. B. et al. Plantas Alimentícias não convencionais (PANC): hortaliças espontâneas e nativas. Porto Alegre: Universidade Federal do Rio Grande do Sul, 2015.

KINUPP, V. F. Plantas alimentícias não convencionais da região metropolitana de Porto Alegre, RS. 2007. Tese (Doutorado do Programa de Pós-Graduação em Fitotecnia). Universidade Federal do Rio Grande do Sul, Porto Alegre, 2007.

KINUPP, V.F.; LORENZI, H. Plantas alimentícias não convencionais (PANC) no Brasil: guia de identificação, aspectos nutricionais e receitas ilustradas. Nova Odessa: Instituto Plantarum de estudos da flora Ltda., 2014.

KINUPP, V. F.; BARROS, I. B. I. Teores de proteína e minerais de espécies nativas, potenciais hortaliças e frutas. Ciência e Tecnologia de Alimentos, v. 28, n. 4, p. 846-857, 2008 .

KINUPP, V. F; BARROS, I. B. I. Riqueza de Plantas Alimentícias Não Convencionais na Região Metropolitana de Porto Alegre, Rio Grande do Sul. Revista Brasileira de Biociências, Porto Alegre, v. 5, supl. 1, p. 63-65, jul. 2007.

KISSMANN, K. G.; GROTH, D. Plantas infestantes e nocivas. 2. ed. São Paulo: BASF, 1999.

KÖPPEN, W.; GEIGER, R. Klimate der Erde. Gotha: Verlag Justus Perthes. 1928. Wall-map $150 \mathrm{~cm} \times 200 \mathrm{~cm}$.

KUNKEL, G. Plants for human consumption: an annotated checklist of the edible phanerogams and ferns. Koenigstein: Koeltz Scientific Books. 1984.

LORENZ, O. A. Lettuce. 1n: The Software Tool works Multimedia Encyclopedia. Version 1.5, Grolier, $\operatorname{lnC}$ 1992. CR-ROM.

LORENZI, H. Plantas daninhas do Brasil: terrestres, aquáticas, parasitas, tóxicas e medicinais. Nova Odessa: Instituto Plantarum de estudos da flora Ltda, 2000.

LUIS, E. Guia de Campo Plantas alimentícias não convencionais. Apostila Hortaliças Não Convencionais. EPAMING Governo de Minas: Manual de Hortaliças Não Convencionais Ministério da Agricultura, Pecuária e Abastecimento. 2010.

MINISTÉRIO DA AGRICULTURA, PECUÁRIA E ABASTECIMENTO (MAPA). Secretaria de Desenvolvimento Agropecuário e Cooperativismo. Hortaliças não convencionais: tradicionais. Brasília: MAPA/ACS. 2010. 
MOREIRA, H. J. da C.; BRAGANÇA, H. B. N. Manual de identificação de plantas infestantes: Hortifrúti. São Paulo: FMC Agricultural Products, 2011. Disponível em: < https://www.fmcagricola.com.br/portal/manuais/infestantes_hf/files/assets/downloads/ publication.pdf >. Acesso em: 04 dez. 2017.

MOU, B. Lettuce. In: PROENZ, J.; NUEZ, F. (Ed.). Vegetables I: Asteraceae, Brassicaceae, Cheonopiaceae, and Cucurbitaceae. New York: Springer Science + Business Media, 2008. p. 75-118.

NONNECKE, I. L. Vegetable Production. New York: Van Nostrand Reinhold, 1989.

ODHAV, B. Preliminary assessment of nutritional value of traditional leafy vegetables in KwaZulu-Natal, South Africa. Journal of Food Composition and Analysis, v. 20, n. 5, p. 430-435, 2007. Disponível em: <http://www.sciencedirect.com>. Acesso em: 08 set. 2018.

PEPPARD, T. L. Volatile flavor constituints of Monstera deliciosa. Journal of Agricultural and Food Chemistry, n. 40, p. 257-262.1992. Disponível em: < http://pubs.acs.org/doi/ abs/10.1021/jf00014a018>. Acesso em: 09 dez. 2017.

PETERS, R. E., LEE, T. H. Composition and physiology of Monstera deliciosa fruit and juice. Journal of Food Science. 42 (4): 1132-1133. 1997.

PHILLIPS, R.; RIX, M. The Random House Book of Vegetables. New York: Random House. N.Y. 1993.

PINK, D. A. C; KEANE, E. M. Lettuce, Lactuca sativa L. In: Genetic Improvement Devegetable Crops. Oxford: Pergamon Press, 1993. p. 543-571.

RANIERI, G. R. (Coord.). Guia prático sobre PANC: plantas alimentícias não convencionais. 1 ed. São Paulo: Instituto Kairós, 2017. Disponível em: <https:// institutokairos.net/wp-content/uploads/2017/08/Cartilha-Guia-Pr\%C3\%A1tico-dePANC-Plantas-Alimenticias-Nao-Convencionais.pdf>. Acesso em: 30 mai. 2018.

RYDER E.J. Lettuce, endive and chicocy. New York: CABI Publishing, 1999.

SCHMEDA-HIRSCHMANN, G. et al. Proximate composition and free radical scavenging activity of edible fruits from the Argentina Yungas. Journal of the Science of Food and Agriculture, v. 85, n. 8, p. 1357-1364, 2005. Disponível em: <http://www. sciencedirectcom>. Acesso em: 09 dez. 2017.

SPADOTTO, C. A.; GOMES, M. A. F.; LUCHINI, L. C.; ANDRÉA, M. M. de. Monitoramento do risco ambiental de agrotóxicos: princípios e recomendações. Jaguariúna: Embrapa Meio Ambiente. Documentos. 2014. Disponível em:< http://www. cnpma.embrapa.br/download/documentos_42.pdf >. Acesso em: 30 mai. 2018. 
SUINAGA, F. A. Desempenho produtivo de cultivares de alface crespa. Brasília, DF: Embrapa, 2013. 15 p. Boletim de Pesquisa e Desenvolvimento / Embrapa Hortaliças.

TERRA, S. B.; DA COSTA, J. E. L. Nível de informação e consumo da população sobre produtos orgânicos em Santana do Livramento, Rio Grande do Sul. Revista Verde de Agroecologia e Desenvolvimento Sustentável. v.12, No 2, p. 311-318, 2017.

WALTER, B. M. T. Coleta de germoplasma vegetal: relevância e conceitos básicos. Brasília: Embrapa, 2005. 